\title{
Review of Legislation for Non-visible Drone Flight
}

\author{
비가시권 드론 비행을 위한 법제 검토 \\ Se-Hun Park ${ }^{1}$ \\ 박세훈1 \\ ${ }^{1}$ Senior Research Fellow, Korea Legislation Research Institute, Republic of Korea, \\ lawpark@klri.re.kr
}

\begin{abstract}
Drones have the advantage of increasing the possibility of access to spaces that are difficult for people, but, there are still a number of challenges to be solved, such as technical defects, collisions caused by poor control, and falls. Unlike in the past that drones were concentrated on military purposes leading the fourth industrial revolution along with autonomous driving and artificial intelligence, drones are now expanding their use to various industries such as unmanned aerial taxis and drones. Drones are a popular industry in various fields around the world due to the innovation and convenience of the technology, and many experts predict that their available fields and ranges will expand in combination with various fields in the future. There are several institutional priorities to revitalize the drone industry, among them, consideration is needed for the appropriateness of non-visible flight regulations that require pilots to visually check the drone's flight status through past manipulation. Non-visual flight, which cannot be identified with the naked eye, can be the foundation of industrial expansion in that it expands the possibility of drone use in areas excluding minimal areas, and will greatly help the people live a safe life through deployment to areas where humans are inaccessible. Focusing on the possibility of developing the drone industry, this study proposed legislative maintenance measures in terms of 'nonvisible flight regulations'."
\end{abstract}

Keywords: Drone, Unmanned Aerial Vehicles, Non-visible Flight, Aviation Safety Act, Safety Standards for Special Flight of Unmanned Aerial Vehicles, Standards for Approval Procedures

요약: 드론은 사람이 접근하기 어려운 공간에 접근 가능성을 높일 수 있다는 장점이 있는 반면, 기술적 결함, 조종 미숙 등으로 인한 충돌 및 추락 등 침해 시에 야기되는 인적·물적 피해에 대한 책임 소재 문제 등 드론과 관련하여 아직 해결해 나가야 할 과제들이 산적해 있다. 드론은 자율주행, 인공지능 등과 더불어 제4차 산업혁명을 최전선에서 이끄는 분야로서 군사 목적으로 집중 활용되어 있었던 과거와는 달리 현재는 무인비행택시, 무선인터넷 보급망 확장, 배송, 농업 등 그 활용이 다양한 산업 분야로 확장되고 있다.

하지만 여전히 드론 산업 활성화를 위한 몇 가지 제도적 선결문제가 있는바, 이 중에서도 특히 과거 조종기 조작을 통해 조종자가 육안으로 드론의 비행상태를 반드시 확인하도록 하는 비가시권 비행 규제의 적절성에 대한 고려가 필요하다. 육안으로 기체 확인이 불가한 ‘비가시권 비행’은 최소한의 영역을 제외한 구역에서의 드론 활용의 가능성을 넓힌다는 점에서 산업 확장의 토대가 될 수 있으며, 재난 상황에서 사람의 접근이 어려운 지역에의 투입을 통해 국민의 안전한 생활을 영위하는 데 큰 도움이 될 것으로 보인다. 이 논문에서는

Received: March 26, 2021; 1st Review Result: May 09, 2021; 2nd Review Result: June 22, 2021 Accepted: July 31, 2021 
드론 산업 발전의 가능성에 초점을 두고, '비가시권 비행 규제' 측면에서의 법제정비 방안을 제안하였다.

핵심어: 드론, 무인비행장치, 비가시권 비행, 항공안전법, 무인비행장치 특별비행을 위한 안전기준 및 승인절차에 관한 기준

\section{1. 서론}

무선으로 조종하는 무인기에 대한 명칭은 국제민간항공기구(ICAO)에서는 RPAS(Remotely Piloted AircraftSystem)로, 미국 연방항공청에서는 UAV(Unmmaned Aerial Vehicle) 등 다양하게 불리나, 우리에게는 '드론'이라는 용어가 더 익숙하다. 「드론 활용의 촉진 및 기반조성에 관한 법률」 (이하: 「드론법」)에 따르면, “드론”이란 ‘조종자가 탑승하지 아니한 상태로 항행 할 수 있는 비행체'를 말하며, 「항공안전법」에서는 '드론'이라는 용어 대신 ‘초경량비행 장치’라는 용어가 사용되고 있다[1]. 드론은 '無人(무인)', 즉 사람이 탑승하지 아니한다는 특징이 있으며, 이에 따라 사람이 접근하기 어려운 공간에 접근 가능성을 높일 수 있다 는 장점이 있는 반면, 기술적 결함, 조종 미숙 등으로 인한 충돌 및 추락 등 침해 시에 야기되는 인적·물적 피해에 대한 책임 소재 문제 등 아직 해결해 나가야 할 과제들이 산 적해 있다. 드론은 자율주행, 인공지능 등과 더불어 제4차 산업혁명을 최전선에서 이끄는 분야로서 군사 목적으로 집중되어 있었던 과거와는 달리 현재는 무인비행택시, 무선인터 넷 보급망 확장, 배송, 농업 등 그 활용이 다양한 산업 분야로 확장되고 있다[2]. 민간 산 업의 목적 외에도 공적 목적으로서 도로, 철도 파손, 교통 장애, 시설물 붕괴, 수질 오염, 수색·구조 등에서 드론 활용 범위는 민관군을 가리지 않고 그 쓰임이 확장되고 있다.

그렇다면 이러한 드론의 기술적 진보 양상을 제도가 충분히 담보하고 있는지에 대해 살펴볼 필요가 있다. 국내외의 드론 관련 제도는 드론의 무인(無人)이라는 특징으로 말미 암아 발생할 수 있는 위험을 관리하기 위한 대상으로 규율하고 있다. 비록 전세계적으로 드론 산업활성화를 위한 규제 완화의 움직임이 있으나, 이는 불과 최근 1 2년 사이의 동 향으로 아직까지 규제 중심의 드론 관련 제도는 계속 운영 중이다. 드론 산업 활성화를 위한 몇 가지 제도적 선결문제가 있는바, 이 중에서도 과거 조종기 조작을 통해 조종자 가 육안으로 드론의 비행상태를 반드시 확인하도록 하는 비가시권 비행 규제의 적절성에 대한 검토가 필요하다. 육안으로 기체 확인이 불가한 '비가시권 비행'은 최소한의 영역을 제외한 구역에서의 드론 활용의 가능성을 넓힌다는 점에서 산업 확장의 토대가 될 수 있 으며, 재난 상황에서 사람의 접근이 어려운 지역에의 투입을 통해 국민의 안전한 생활을 영위하는 데 큰 도움이 될 것으로 보인다. 이를 위해 이 논문에서는 국내외 드론 비가시 권 비행 규제 현황을 살펴봄으로써, 추후 논의할 법제정비 방안의 개략적 방향을 탐색하 였다. 이를 바탕으로 이 논문에서는 드론 산업 발전의 가능성에 초점을 두고, '비가시권 비행 규제, 측면에서의 법제정비 방안을 제안하고자 한다.

\section{2. 드론의 비가시권 비행 규제 현황}

\section{1 해외}

여기에서는 미국과 일본의 사례를 살펴보았는데, 이는 두 국가에서 선제적으로 드론의 
비가시권 비행 규제에 관심을 가지고, 산업 발전을 위한 규제에 대응하고 있기 때문이다.

\subsection{1 미국}

미국에서도 드론 산업의 활성화를 위한 다양한 방법들이 진행되고 있다. 그 중 비가시 권 드론의 활용은 예전부터 운송 및 감시를 비롯한 상업 드론 사업에 반드시 필요한 부 분으로 평가되고 있었으나, 소형 무인항공기 규정인 FAA 14 CFR Part §107.31, §107.33[3]에 따라 비가시권에서의 드론의 운행을 금지하고 있다. “드론을 운항 중인 원격 조종사 및 비행 제어를 조작하는 모든 사람은 드론이 비행 중에 있는 경우 직접 드론을 볼 수 있어 야 한다"라고 명시하고 있다. 이렇듯 일반적으로는 비가시권 드론 운항은 금지시키고 있 으나. 미국연방항공청(FAA)에서는 Part 107 Waiver(제107조 특별면제)프로그램을 2016년 8 월부터 운영하고 있다[4].

미국연방항공청에 제 107 조 면제 절차에 따라 비가시권 드론을 운용하려는 사업자가 신 청하여 면제받고자 하는 드론의 비행이 공중에 있는 다른 드론 및 항공기에 영향을 미치 지 않는지 여부와 지상에 있는 인명 및 재산에 피해에 대한 위험으로부터 자유롭다는 것 을 증명하는 신청서를 제출하고, 미국연방항공청의 조사를 통하여 비가시권 비행을 허가 하고 있다. 비가시권 드론 운영 규정 특별 면제는 다른 면제 프로그램 보다 승인 허가가 쉽지 않다. 즉 공공의 필요성이 강한 경우를 제외하고 비가시권 드론 운영 면제를 신청 한 업체의 약 $90 \%$ 가 승인이 거절되며, 승인 거절 이유로는 기술적 안정성이 가장 큰 원 인으로 지목되고 있는 것으로 보고되고 있다[5]. 다만 공공의 안전을 위하여 사용되는 드 론에 대해서는 비가시권 비행을 최근 허용하고 있는바, 인간의 생명을 보호하기 위하여 무인항공기를 운항하는 경우 비가시권 비행을 허용하는 규정인 $14 \mathrm{CFR} 91.113(\mathrm{~b})$ 을 개정하 였다[6]. 이에 따라 최근 자동심장충격기 전달용 드론에 대한 비가시권 비행을 허가한 사 례가 있으며, 대형 화재 구조 현장에서의 수색을 수행하거나 우거진 숲이나 산에서의 실 종된 사람을 찾기 위한 비가시권 비행이 가능하다. 다만 비행 중인 드론은 조종사로부터 1,500 피트 $(450 \mathrm{~m})$ 이상 운행하는 것은 금지되어 있다[7].

미국에서도 역시 드론 산업의 발전과 관련하여 드론 사업자 중심으로 드론의 비가시권 비행에 대한 규제 완화에 관심이 매우 높다. FAA는 최근 식별장치 탑재를 전제로 그간 금지했던 야간비행을 허용한 바 있으며, 바가시권 비행 규제 역시 완화 추세에 있다. 향 후 수백 $\mathrm{Km}$ 의 전력라인, 파이프라인, 오일 및 가스관, 송유관 및 송수관을 점검하고 관 리를 위한 비가시권 드론 산업이 발전할 것으로 기대된다.

\subsection{2 일본}

비가시권 드론 비행을 엄격히 금지하던 일본이 2018년 9월 장거리 산업 드론 작동을 위해서는 조종사 또는 기체를 감시하는 조력자가 육안으로 기체를 확인할 수 있는 범위 내에서만 드론 비행이 허용된다"라는 조문을 폐지하기로 하고 비가시권 드론 운항에 대 한 규제를 완화하였다. 또한 2018년 9월에 국토교통성은 후쿠시마현 소고(小高) 우체국과 나미에(浪江) 우체국 사이 $9 \mathrm{Km}$ 구간에서 이뤄지는 비가시권 실험 비행을 승인하였다[8]. 일본 「국토교통성 항공국에서 무인항공기(드론, 무선 조종기 등)의 안전한 비행을 위한 가이드라인」을 제시하고 있는바, 본 가이드라인의 주요 시사점으로는 비행금지 공역을 정하고 있고, 지표 또는 수면으로부터 $150 \mathrm{~m}$ 이상의 공역과 공항 주변의 공역, 모든 공항 이나 헬리포트 등에서의 진입 금지 등 구체적으로 제시하고 있으며, 이를 지키지 않으면 항공법의 규정을 준용하여 50 만엔 이하의 벌금 또는 1 년 이하의 징역을 규정하여 강하게 
강제하고 있음을 알 수 있다[9].

특히 비가시권 비행 규제와 관련하여서도 일본은 발빠르게 대응하고 있다. 일본은 드론 비행 규제를 4단계 레벨로써 나누고 있다. 구체적으로 레벨 1(육안에서의 조종 비행)-레 벨 2(육안에서의 자동·자율 비행)-레벨 3(타인이 들어갈 가능성이 낮은 장소에서의 육안외 비행)-레벨 4(유인 지대에서 육안외비행)으로 구분된다. 이 중 마지막 단계인 레벨 4에 대 해 2022년까지 도심 내 비가시권 비행이 가능하도록 하기 위한 제도를 정비하고 있다[10]. 현재 일본 국토교통성은 비가시권 비행을 위해 기체의 안전성을 인증받는 것과 조종자의 면허를 새롭게 개선하는 방안으로 항공법 개정안을 제시하였다.

\section{2 국내 비가시권 비행 법체계 검토}

해외의 경우, 비가시권 드론 운영에 대한 제도적 제한점을 점진적으로 완화하는 추세 (미국)와 적극적으로 제도 개선을 추진하는 경우(일본)로 구분할 수 있다. 국내의 경우에 는 전자의 방향으로 이루어지고 있다. 국내 드론 비가시권 비행 허용은 관련 법령(예, $\ulcorner$ 항공안전법」 등)에는 명시되어 있지 않으나, 국토교통부 고시를 통해 비가시권 비행을 정의하고, 이의 승인 절차 및 기준을 명시하고 있다[11].

항공기, 경량항공기 또는 초경량비행장치의 안전하고 효율적인 항행을 위한 방법과 국 가, 항공사업자 및 항공종사자 등의 의무 등에 관한 사항을 규정함을 목적으로 하는 $\ulcorner$ 항공안전법」 은 초경량비행장치의 조종자에게 초경량비행장치로 인하여 인명이나 재 산에 피해가 발생하지 아니하도록 국토교통부령으로 정하는 준수사항을 지키도록 하고 있다(제 129 조 제 1 항). 비가시권 비행의 허용 여부와 관련하여 동법 시행규칙에서는 초경 량비행장치 조종자는 다른 항공기 또는 경량항공기를 육안으로 식별하여 미리 피할 수 있도록 주의하여 비행하여야 하며(동 시행규칙 제 310 조 제 2 항), 무인비행장치 조종자는 해당 무인비행장치를 육안으로 확인할 수 있는 범위에서 조종하여야 한다(동조 제4항). 다만, 법 제124조 전단[12]에 따라 연구 - 개발이나 안전성평가 등을 위한 시험비행의 허 가를 받아 비행하는 경우는 제외함으로써, 결과적으로 원칙상 육안으로 확인할 수 있는 범위에서만 드론을 조종하여야 하고, 예외적으로 상용이 아닌 일부 시험목적에 한정하여 서만 비가시권 비행이 가능하다.

한편, 비가시권 비행과 관련하여서는 「항공안전법」에 별도의 정의를 마련하고 있지 않고, 국토교통부 고시인 「무인비행장치 특별비행을 위한 안전기준 및 승인절차에 관한 기준」(이하 특별비행기준) 제 2 조 제 3 호에서 정의하고 있는바, “가시권 밖 비행’이란 무인 비행장치 조종자가 해당 무인비행장치를 육안으로 확인할 수 있는 범위의 밖에서 조종하 는 행위를 말한다"고 명시하고 있다[13]. 「항공안전법」은 비가시권비행 등을 원칙적으 로 금지함에도 불구하고 일말의 예외를 두어 국토교통부령으로 정하는 일정 요건을 충족 할 경우 장관의 승인을 받아 그 승인 범위 내에서 예외적으로 비행이 가능하도록 규정하 고 있다(제129조제5항)[14]. 앞서 특별비행기준은 이러한 비가시권 비행 등을 승인하기 위 한 요건 및 절차를 규정하고 있는 것으로서 제 5 조에 따라 항공안전기술원장에게 안전기 준 검사를 통과한 기체의 조종자가 특별비행승인 신청서를 작성하고 다음의 서류를 첨부 하여 지방항공청장에게 제출할 것을 정한다(동 기준 제4조)[15].

[표 1] 특별비행승인 신청 시, 첨부 서류

[Table 1] Attached Docunets when Applying for Non-visible Drone Flight 
1. 무인비행장치의 종류·형식 및 제원에 관한 서류

2. 무인비행장치의 성능 및 운용한계에 관한 서류

3. 무인비행장치의 조작방법에 관한 서류

4. 무인비행장치의 비행절차, 비행지역, 운영인력 등이 포함된 비행계획서

5. 안전성인증서

6. 무인비행장치의 안전한 비행을 위한 무인비행장치 조종자의 조종 능력 및 경력 등을 증명하는 서류

7. 제 3 자 손해 발생 시 손해배상 책임을 담보하기 위한 보험 또는 공제 등의 가입을 증명하는 서류

8. 초경량비행장치 비행승인신청서

9. 비상상황 매뉴얼 및 운영인력의 비상상황 훈련 이수 증빙서류

10. 무인비행장치 이·착륙장의 조명 및 장애물 등 현황에 관한 서류

11. 그 밖에 특별비행 안전기준에 적합함을 입증할 때 필요한 서류

세부적인 절차를 살펴보면 지방항공청장은 위의 서류를 제출받은 날부터 30 일(새로운 기술에 관한 검토 등 특별한 사정이 있는 경우에는 90 일) 이내에 무인비행장치 특별비행 을 위한 안전기준에 적합한지 여부를 항공안전기술원장에게 감사의뢰 및 완료[16]한 후 적합하다고 인정하는 경우에는 무인비행장치 특별비행승인서를 발급하여야 한다. 이 경 우 지방항공청장은 항공안전의 확보 또는 인구밀집도, 사생활 침해 및 소음 발생 여부 등 주변 환경을 고려하여 필요하다고 인정되는 경우 비행일시, 장소, 방법 등[17]을 정하 여 승인할 수 있다(시행규칙 제 312 조의 2 제 2 항).

결과적으로 비가시권 비행은 이러한 절차를 거친 후 이루어지는 특별비행승인을 통하 여야만 가능하다는 것으로, 명시된 사항 외에도 계획 변경 등 추가적으로 수반되어야 하 는 절차가 있는 만큼 그 절차가 매우 복잡하고 안전을 이유로 요구되는 기술과 구비서류 또한 그 종류와 분량이 많아 이러한 규제가 지속될 경우 향후 드론 산업 발전에 큰 걸림 돌이 될 것으로 판단된다[18].

\section{3. 비가시권 규제 완화를 위한 법제정비 방안}

\section{1 개정의 필요성}

\subsection{1 드론 개념상의 문제}

현행「항공안전법」 에서의 드론 조종자의 비가시권 드론 비행에 대한 규제는 조종자 가 조종기를 통해 원격에서 드론을 제어하는 기존 운용 방식을 고려하여 안전한 비행 및 신속한 사고대응 등을 목적으로 제정된 규정으로, 드론 비행에 따른 인명·재산상의 피해 가 발생하는 것을 방지 또는 최소화할 수 있다는 장점이 있다. 또한 드론 사고 발생 시, 드론 추락 지점 부근으로 조작자의 위치가 확정될 수 있으므로 책임 소재를 더 명확히 할 수 있다는 점에서 본 규제의 실익이 있을 수 있다. 그러나 일반적으로 드론은 그 기 술의 발전에 따라 드론의 개념이 조종사가 비행체에 탑승하지 않고 원격으로 조종하는 기존의 원격조종항공기시스템(RPAS) 뿐만 아니라 원격 조종사가 없는 자율비행시스템 (AUAS)까지 포함하고 있다는 점에서 현행 드론 개념과 위 규정은 부합하지 않는다. 일례 로「드론법」 제2조제1항제1호다목에서는 “드론”을 ‘원격·자동·자율 등 국토교통부령으 로 정하는 방식에 따라 항행하는 비행체'로 정의하고 있다[19]. 또한 국외에서의 드론에 대한 법령상 정의에도 역시 ‘자율조종’이 포함되어 있다[20]. 이 외에도 과학기술정보통신 부에서 2018년 제안한 「무인이동체 기술혁신과 성장 10 개년 로드맵」에서 무인이동체 6 대 공통핵심기술 중 하나로 ‘자율지능'을 도출한 것을 통해서도 “드론”의 특징 중 하나가 ‘자율비행’임을 알 수 있다. 이처럼 드론의 개념이 '사람의 도움 없이 스스로 조종 및 항 법을 수행하는 이동체'로 그 의미가 확장되고 있는데, 이러한 원격 조종사가 없는 자율비 
행시스템이란 비가시권 비행까지 전제로 하므로 이에 현재의 비가시권 비행 금지는 드론 의 정의 규정과 부합하지 않는다. 이처럼 현재 자율비행까지 포괄하는 드론의 개념과 현 행 법령에서의 비가시권에 대한 드론 비행 관련 규정이 부합하지 않는다는 점에서 비가 시권 규제 완화에 대한 법제정비가 필요함을 알 수 있다.

\subsection{2 기술의 고도화}

드론의 비가시권 비행이 문제가 되는 이유 중 하나는 조종자의 드론 악용 비행에 따른 책임 소재의 불분명에 의한 것이다. 또한 드론 비행의 안전성 확보 역시 비가시권 비행 을 제한하는 하나의 요인으로 작용한다. 그러나 현재 전 세계적으로 불법 드론 대응기술 을 개발하고 있으며, 국내의 경우 과학기술정보통신부는 2020년 12월 「불법드론 지능형 대응기술개발사업」 추진계획 및 2021년도 시행계획(안)을 통해 3 단계에 걸친 안티드론 기술 강화를 통한 안전성 확보를 위한 정책을 추진하고 있다[21]. 또한 해당 계획에서 기 반을 두고 있는 기술인 포렌식 기반 증거 분석은 조종자 추적이 가능하다는 점에서 드론 이용 범죄 책임자의 소재를 파악하기 위한 부처의 노력을 확인할 수 있다[22]. 드론 비행 안전성과 관련하여 비가시권에서 비행되는 드론의 경우, 위치 식별의 어려움, 통신 혼란 등에 따른 추락 위험 등 다양한 유형의 사고 발생 가능성이 커짐에 따라, 드론의 비가시 권 비행을 규제하였다. 그러나 현재 고도화되고 안정적인 전파 환경 하에서는 기존 조종 기와의 직접 통신에 의존하였던 드론 운용방식에서 벗어나 전파 중계 장치와의 통신을 통한 실시간으로 상태 확인이 가능한 자율비행까지 가능하며, 드론 기술 역시 비가시권 비행이 가능하게 고도화되어 있으며, 특히 Geofencing 기술을 통해 비가시권 비행으로도 특정 공역 내에서 드론 비행이 가능하다. 또한 안전 문제와 관련하여 기체 이상시 자동 으로 이륙 지점으로 복귀하도록 프로그램이 준비되어 있는 수준에 이르렀다는 판단이다. 이처럼 기술의 발전은 드론의 안전성을 담보하고 있다고 하겠으나, 현행 제도는 오히려 이를 따라가지 못하는 상황에 놓여 있음으로, 드론 기술의 발전을 제도적으로 보장한다 는 측면에서 개정이 필요한 상황에 놓여있다.

\subsection{3 드론 활용 영역의 확대}

드론 산업은 민수용·군수용에 관계없이 그 시장규모는 확대되고 있으며, 그 성장 전망 역시 밝을 것으로 예측한다[23]. 기존 레저 목적의 이용이나 단순 촬영 목적의 이용에서 더 나아가 현재 드론 산업은 사람(드론 택시)이나 물건(드론 택배)의 장거리 이송이나 인 공지능과 결합한 다양한 사업 모델로 확장되고 있다. 우버이츠의 배송용 드론, 우버 에어, 아마존 프라임 에어 등과 같이 국외에서뿐 아니라 국내에서도 2020년 국토교통부에서 2025년 차세대 모빌리티인 드론 택시 상용화를 목표로 한 「한국형 도심항공교통(K-UAM) 로드맵」을 발표하였다[24]. 그러나 이러한 드론 산업의 발전은 대부분 상업용 목적으로 서 비가시권 비행을 전제로 두고 있어, 비가시권 비행에 대한 안전성을 확보하게 되면 규제적 부분의 해결 및 산업 발전적 측면에서도 선제적으로 검토해야 한다. 이에 미국 연방항공청의 경우 드론 식별장치 부착을 전제로 야간비행을 제한적으로 허용하고 있는 등 국외 비가시권 비행에 대한 규제는 점차 완화되고 있다. 즉, 미국에서는 드론 배송 업 체가 '규정 135 (드론의 상업용 정기 및 전세 운항 요건 적시)'에 따른 인증을 취득할 경 우 '비가시권 운항 가능'에 대한 법적 권한을 가질 수 있다. 이처럼 드론의 비가시권 비 행에 대한 규제 완화는 드론 활용 영역 확대에 따른 드론 산업 발전, 더 나아가 국가 경 쟁력 강화라는 긍정적 효과를 가져올 수 있을 뿐 아니라, 친환경 수송 수단으로서 이는 
전 세계적으로 심각한 기후 위기를 해결해야 할 현시점에 또 다른 해결 방안으로 제시할 수 있다는 장점이 있다[25].

\subsection{4 현행 특별승인제도의 문제점}

$\ulcorner$ 항공안전법」 제 129 조, 동법 시행규칙 제 310 조제 1 항 및 제 4 항에서는 드론의 비가시권 비행을 법적으로 금지하고 있다. 그러나 이러한 행위는 예외적으로 무인비행장치 특별비 행승인을 득함으로써 허용된다. 특별승인제도와 관련된 국내 법 조항으로는 「항공안전 법」 제 129 조제 5 항, 동법 시행규칙 제 312 조의 2 를 들 수 있다. 또한 국토교통부고시 제 2020-984호 ‘무인비행장치 특별비행을 위한 안전기준 및 승인절차에 관한 기준' [별표 1] 에 제시된 특별비행 안전기준을 충족할 경우 비가시 비행이 가능하다[26]. 현행 특별승인 제도는 신청자가 특별비행승인을 신청하면 접수기관(지방항공청)에서 이를 확인한 뒤, 검 사기관인 항공안전기술원에 검사 의뢰를 한다. 이후 검사기관에서 비행점검 및 현장검사 를 수행한 뒤, 그 결과를 접수기관에 제출하고, 접수기관은 승인서를 발급하여 신청자에 게 발급하는 방식으로 이루어진다. '신청자 $\leftrightarrows$ 접수기관 $\lessgtr$ 검사기관' 간 승인을 위한 단계 를 이행함에 대략 한 달 정도의 시간이 걸린다(특별한 사정이 있는 경우는 90 일 소요). 승인 기간의 문제뿐 아니라, 해당 제도의 승인 요건[27]과 절차[28]가 매우 까다롭다[29].

‘장기간 소요', ‘까다로운 승인 요건 및 절차'는 드론 사업의 효율성 등의 문제로 이어질 수 있다. 한편 국내 특별비행승인 제도의 경우, 기체 및 현장검사 시 '관찰자 유무 및 위 치'를 확인한다. 그러나 일본 국토교통성은 택배 산업에서의 드론 활용 범위를 산간, 도 서 지역 택배 등에서는 '보조자 없는 비가시권 비행'을 승인하는 등[30] 드론 비가시권 비행 승인 조건이 국내보다 상대적으로 완화되어 있음을 알 수 있다. 드론 산업의 발전 및 활용 가능성이 확대될 것으로 전망되는 현재, 국내에서도 드론의 적극적 활용에 따른 산업 발전을 위해 일본과 같이 비가시권 내 드론 비행 승인 조건을 완화할 필요가 있다.

\section{2 비가시권 비행을 위한 개정안 제언}

지금까지 살펴본 국내 드론 비가시권 운행을 위해서는 다음과 같은 두 방향으로의 법 적 개정을 제안할 수 있다. 첫째, 제 1 안은 원칙적 금지를 유지하되 특별승인제도를 개정 하여 비가시권 비행이 필요한 드론 사업자의 경우 1 회 심사 후 승인 시 일정기간 동안 별도 승인 없이 비행 가능하도록 하는 방향으로의 개정이다. 둘째, 제 2 안은 미국 연방항 공청과 마찬가지로 드론 식별장치 부착을 전제로 비가시권 비행이 가능하도록 개정하는 것이다. 우선 제 1 안에 대해 살펴보면 현행 특별승인제도의 문제점으로 '장시간 소요', ‘까 다로운 승인 요건 및 절차뿐 아니라 특별비행승인 인증의 유효기간이 최대 6개월 범위 내로 제한되어 있다[31]. 유효기간의 연장 시, 그 기간 역시 최대 6개월 범위 내로 하며 이때, 특별비행승인에 대한 검사 및 승인 절차를 다시 따라야 한다[32]. 이러한 현행 특별 비행승인제도의 문제해결에 초점을 둔 개정 방향이 제 1 안의 내용이다.

[표 2] 비가시권 비행을 위한 개정안(1안)

[Table 2] Amendment for Non-visible Flight( $1^{\text {st }}$ draft $)$

\begin{tabular}{|c|c|c|}
\hline 현행 & & 개정(안) \\
\hline $\begin{array}{l}\text { 제7조(특별비행승인 유효기간) 특별비행승인의 유효 } \\
\text { 기간은 신청자가 제출한 비행계획서 상의 기간으로 } \\
\text { 하되, 최대 6개월의 범위 내로 한다. }\end{array}$ & $\rightarrow$ & $\begin{array}{l}\text { 제7조(특별비행승인 유효기간) 특별비행승인의 유효 } \\
\text { 기간은 신청자가 제출한 비행계획서 상의 기간으로 } \\
\text { 하되, 최대 } \mathbf{1 2} \text { 개월의 범위 내로 한다. }\end{array}$ \\
\hline
\end{tabular}


제8조(특별비행승인서 변경 및 연장) (1) 생략

(2) 생략

(3) 변경 또는 연장된 특별비행승인의 유효기간은 변경·연장 신청 시에 제출한 비행계획서 상의 기간 으로 하되, 최대 6개월의 범위 내로 한다.

(4) <신 설>
제8조(특별비행승인서 변경 및 연장) (1) 생략

(2) 생략

(3) 변경 또는 연장된 특별비행승인의 유효기간은 변 경·연장 신청 시에 제출한 비행계획서 상의 기간으

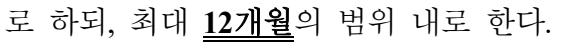

(4) 특별비행 조건을 6 개월 동안 안정적이고 지속적 으로 운행한 비행은 12 개월 범위 내에 제2항을 준용 한 것으로 본다.

다음으로 제 2 안에 대해 살펴보면, 미국은 최근 드론 원격식별을 위한 요구사항과 관련 법안(Remote Identification of Unmanned Aircraft System)을 공시하였고 곧 확정하여 제시할 예 정에 있다[33]. 이처럼 2019년 미국 연방항공청은 원격식별을 위한 규칙 결정 통보(NPRM) 를 통해 2020년부터 FAA Airman Certificate 취득을 위한 시험 전, FAA Tracking Number(FTN) 를 부여받아야 하도록 법을 개정하였다[34]. 이에 상업용 드론 운영에서 연방 정부 규정 135 인증을 받으면, ‘비가시권 운항'뿐 아니라 ‘주야간운항, 무제한 횟수 운항, 55파운드 이 상 물품 적재, 등에 대한 법적 권한을 부여받을 수 있다[35].

[표 3] 비가시권 비행을 위한 개정안(2안)

[Table 3] Amendment for Non-visible Flight $\left(2^{\text {nd }}\right.$ draft $)$

\begin{tabular}{|c|c|c|}
\hline 현행 & & 개정(안) \\
\hline $\begin{array}{l}\text { 제 } 122 \text { 조(초경량비행장치 신고) (1) (5) 현행 } \\
\text { (6) <신 설> }\end{array}$ & $\rightarrow$ & $\begin{array}{l}\text { 제122조(초경량비행장치 신고) (1) (5) 현행 } \\
\text { (6) 제129조제7항에 해당하는 무인동력비행장치소유 } \\
\text { 자등은 신고 시, 제129조제7항에 따른 무인동력비 } \\
\text { 행장치 원격식별 요건을 충족함을 증명해야 한다. }\end{array}$ \\
\hline
\end{tabular}

한편 기체에 부착하는 원격식별 장치에는 조종자 이름, 주소 등 주요 정보 저장이 가 능할 뿐 아니라, 기타 보안 기능 등이 있어[36] 비가시권 비행에서 발생할 수 있는 문제 에 대한 책임소재를 분명히 할 수 있다. 이에 국내 역시 드론 식별장치 부착을 전제로 비가시권 비행이 가능하게 하는 것이 제 2 안의 내용이다.

\section{4. 결론}

드론에 대한 규제는 다양한 국가에서 매우 유사한 형식으로 이루어지고 있다. 특히 비 가시권 비행의 경우 그 안전성의 이유로 대체로 금지하고 있으며, 공공의 안전이라는 목 적에 비추어 볼 때, 이러한 규제의 타당성을 인정할 수 있다. 다만, 앞서 살펴본 바와 같 이 드론 기술의 발전으로 인해 비가시권 비행 시 드론의 안전수준이 일정 수준 이상 담 보된 현재 상황에서 과거와 동일한 수준의 규제를 지속한다는 것은 향후 잠재적 활용 가 능성이 큰 드론 산업의 발전에 걸림돌로 작용할 여지가 있다. 비록 우리나라의 경우 특 별비행승인이라는 제도를 통해 예외적으로 비가시권 비행을 인정하고는 있지만, 절차의 복잡성 및 높은 기술 수준 요구로 인해 사실상 상업 드론에서의 제도 활용 가능성이 낮 다고 본다. 이 논문에서는 이러한 문제점을 검토하고 이를 해소할 수 있는 최소한의 개 정 방향성을 제시하였다. 다만, 특별비행승인의 단순 기한 연장에 더하여 요구서류-절차 등에 대한 간소화가 필수적으로 수반되어야 하는바, 이는 제도 연구에 더해 절차생략 및 
간소화에 대한 타당성을 집행권자의 입장에서 자세히 검토한 후 이에 대한 제언이 가능 할 것으로 보인다. 본 연구는 아직 국내에서 활성화되지 않은 드론의 비가시권 비행 규 제에 대한 문제점 등의 논의를 본격적으로 언급한 초기 연구로서 의미가 있으며, 향후 집행기관, 산업계 등의 다양한 의견 수렴을 통해 보다 발전적인 방안의 도출이 가능할 것으로 판단된다.

\section{References}

[1] www.law.go.kr, May 11(2021)

[2] Commercializations Promotion Agency for R\&D Outcomes, Drone Technology and Market Trend Report, Korea: Commercializations Promotion Agency for R\&D Outcomes, (2019)

[3] https://www.ecfr.gov/cgi-bin/text-idx?node=pt14.2.107\&rgn=div5\#se14.2.107_131, May 16 (2021)

[4] https://www.faa.gov/uas/commercial_operators/part_107_waivers/, May 16 (2021)

[5] https://www.precisionhawk.com/blog/media/topic/why-99-of-bvlos-part-107-waivers-are-rejected, May 16 (2021)

[6] http://www.irobotnews.com/news/articleView.html?idxno=15387, May 16 (2021)

[7] https://www.ecfr.gov/cgi-bin/text-idx?node=14:2.0.1.3.10, Aug 9 (2021)

[8] https://www.ecfr.gov/cgi-bin/text-idx?node=14:2.0.1.3.10, Aug 9 (2021)

[9] https://www.mlit.go.jp/koku/koku_tk10_000003.html, Aug 9 (2021)

[10] https://www.kantei.go.jp/jp/singi/kogatamujinki/kanminkyougi_dai9/sankou2.pdf, Aug 9 (2021)

[11] Ministry of Land, Infrastructure, Transport and Tourism-Civil Aviation Bureau, Guidelines for safe flight of Unmanned Aerial Vehicle, radio-controlled models, ect, (2019), https://www.mlit.go.jp/common/001287979.pdf/, May 16 (2021).

[12] AVIATION SAFETY ACT, Article 124(Safety Certification of Ultra-Light Vehicle)

[13] Ministry of Land, Infrastructure, Transport and Tourism, Safety standards and approval procedures for special flight of unmanned aerial vehicles, Ministry of Land, Infrastructure and Transport Notice2020-984

[14] AVIATION SAFETY ACT, Article 129, Vol.1.

[15] Safety standards and approval procedures for special flight of unmanned aerial vehicles, Article 4 (Safety standards and Application documents)

[16] Safety standards and approval procedures for special flight of unmanned aerial vehicles, Article 5 (Safety standards inspection)

[17] Safety standards and approval procedures for special flight of unmanned aerial vehicles, Article 6 (Approcal of special flight)

[18] https://www.boannews.com/media/view.asp?idx=69861\&kind=3, May 16 (2021)

[19] http://www.law.go.kr, May 11 (2021)

[20] S. Y. Lee, W. Kang, A Study on the Reestablishment of the Drone's Concept, Korean Security Journal, (2019), Vol.58, pp.35-58. https://www.koreascience.or.kr/article/JAKO201913261020891.page

[21] Ministry of Science and ICT, Illegal drone intelligent response technology development project [based on dronecop and live forensics] promotion plan and implementation plan for 2021, Korea: MSIT

[22] Ministry of Science and ICT, Protect important facilities such as nuclear power plants and airports from illegal drones, Korea: MSIT Press Release, (2021.04.19.) 
[23] Y. S. Ahn, J. H. Jeong, Recent trends and major issues in the drone and personal aircraft(PAV) industry, Korea: Korea Institue for Industrail Economics \& Trade, (2020)

[24] Ministry of Land, Infrastructure and Transport, In 2025, the 'CITY SKY ROAD’ without fraffic jams will be opened, Korea: MOLIT Press Release, (2020.06.04.)

[25] Relevant Ministries, Korean Urban Air Traffic (K-UAM) Technology Roadmap, Korea: Relevant Ministres, (2021)

[26] Safety standards and approval procedures for special flight of unmanned aerial vehicles, Article 4 (Safety standards and Application ducuments)

[27] AVIATION SAFETY ACT, Enforcement Rules Article 312-2

[28] https://www.kiast.or.kr/kr/sub06_06_01_01.do, May12 (2021)

[29] https://www.kiast.or.kr/kr/sub06_06_01_01.do, May 12 (2021)

[30] H. J. Kang, Drone Delivery Service Commercialization Plan Study, The Korean Jornal of Air \& Space Law and Policy, (2020), Vol.53, No.2, pp.281-312.

[31] Safety standards and approval procedures for special flight of unmanned aerial vehicles, Article 7 (Period of validity of special flight approval)

[32] Safety standards and approval procedures for special flight of unmanned aerial vehicles, Article 8 (Change and extension of special flight authorization)

[33] S. H. Park, S. Y. Lee, J. H.Kim, I. S.Yoon, J. S.Ryu, S. S.Park, W. Kang, D. K.Lee, J. B.Seo, W. J.Son, W. M.Nam, J. H.Park, N, K.Kim, J. E.Kim, S. H.Tak,S. G. Lee, H. K.Jang, C. M.Song, J. O.Kim, Y. B.Jeong, A study on the demand for operation of low-altitude small drones and the number of parking spaces foridentification and system improvement, Korea: National Radio Research Agency, (2020)

[34] http://koreascience.kr/article/JAKO202030060640789.pdf, May 12 (2021)

[35] The Korea Transport Institue, FAA derefulates drones...Allow night delivery, Global Logistics Technology Trend, (2021), Vol.14, No.647, pp.15-16.

[36] Y. S. Kang, K. W. Kim, J. H. Kim, S. J. Lee, Drone Identification Module (DIM) Technology and Standardization Trend, Journal of the Korea Institute of Information Security \& Cryptology, (2020), Vol.30, No.2, pp.5-9. 